\title{
Implementing the European Quality Assurance in Vocational Education and Training (EQAVET) at National Level: Some Insights from the PEN Leonardo Project ${ }^{1}$
}

\author{
Suzanne Gatt* \\ University of Malta \\ Faculty of Education \\ Msida, MSD 2080, Malta \\ E-mail: suzanne.gatt@um.edu.mt
}

\author{
Kim Faurschou \\ Faco \\ Institute of Education \\ Aloekken 24, DK 5250 Odense SV, Denmark \\ E-mail: faco@spo.dk \\ * Corresponding author
}

Received: 15 October 2015; Accepted: 17 December 2015; Published online: 30 April 2016

\begin{abstract}
EQAVET, the quality assurance tool in vocational and educational training, was developed in response to the need for a supply of a trained workforce for labour market needs. Implementation of EQAVET at national level, however, remains a challenge. The research reported here focused on the implementation of QA processes by VET providers in 4 countries: Malta, Italy, Turkey, and Sweden. Data was collected through a questionnaire with 62 VET providers. Responses showed that there is an overall commitment to quality. There is, however, little knowledge of EQAVET across the countries, with the exception of Malta. None the less, all VET providers have implemented some aspects of EQAVET, even if not always intentionally. The situation is, however, far from EQAVET being fully implemented. Reflections are made on whether the EQAVET model specifically or qualification assurance principles assurances should be promoted across Europe.
\end{abstract}

Keywords: VET, Quality Assurance, EQAVET, Quality Cycle, Vocational Education and Training

\section{Bibliographical notes:}

Prof Suzanne Gatt is an Associate Professor at the Faculty of Education at the University of Malta, Malta. Her research interests focus on quality assurance, qualifications frameworks and apprenticeships.

\footnotetext{
${ }^{1}$ This report has been produced as part of the activities within the project Pathway from EQAVET to NQAVET - PEN Project funded under the call for proposals 2013 Leonardo do Vince Programme: Leonardo multilateral project for development of innovation.
} 
Mr Kim Farschou is an independent consultant from Denmark. His research interests focus on quality assurance, being an active player in the Copenhagen process. 


\section{Introduction}

Europe is currently facing fast-changing technical developments and an ever increasing global competition (Boden et al., 2010). Europe can only live up to this challenge by equipping learners, particularly those within vocational education and training (VET) with the skills required for the jobs of today as well as those of tomorrow (OECD, 2010). There is the need to enhance the responsiveness of education and training systems to these changes in terms of skill requirements. This is particularly important as young people across Europe are experiencing a more difficult transition from education to the labour market as a consequence of the financial crisis (Jørgensen, 2014).

Investment in education is an effective means through which Europe can keep pace with international competition, as well as contribute to increased social cohesion in the current crisis (European Commission, 2010). Governments have already invested in VET systems to change them from a second-choice option for school drop-outs to a way of addressing the skills required by economies (Seyfried, 2008). However, financial investments alone are not sufficient to make VET attractive, socially inclusive and competitive. VET needs to ensure quality in its provision. Quality assurance (QA) in VET gains importance as it is the mechanism through which there is assurance for the provision of a well-trained workforce (Galvao, 2014).

QA in VET at European level was first highlighted by the Lisbon Strategy 2000-2010 (Lisbon Special European Council, 2000), with the objectives for VET formulated in the Copenhagen Declaration (European Ministers of VET and European Commission, 2002). Significant work at European level has since been achieved, with the development of QA tools and methods. This work led to the Recommendation of the European Parliament and of the Council (European Parliament and Council, 2009) which established the European Quality Assurance Reference Framework for Vocational Education and Training (EQAVET) in 2009.

The main challenge for EQAVET is its national implementation across Member States. A study on the national implementation of EQAVET across EU Member States showed that most countries have developed or are currently developing policies, structures and processes to devise and establish their national approaches at system level. Less progress was registered at provider levels (EQAVET Secretariat, 2013). This paper provides some insights directly from VET providers in a number of European Countries: Italy; Sweden; Malta; and the non-EU country Turkey. It presents research results from part the Leonardo project 'Pathway from EQAVET and NQAVET' - PEN funded by the European Commission within the Lifelong Learning Programme.

The project PEN addresses one of the major challenges related to QA in VET: that of promoting the implementation of European developments among VET providers within EU Member States. The results of this research and other further activities feed into the overall goal of the project which is to increase transparency in European VET by enhancing the development of National Quality Guidelines/ recommendations and approaches for VET (NQAVET) provider level based on EQAVET.

\section{Theoretical Background}

Ever since the Lisbon strategy was formulated in 2000, there has been a clear European focus on VET. The Copenhagen declaration (European Ministers of VET and European Commission, 2002) which followed highlighted the need to focus on 
quality in VET. Transparency, competitiveness and the creation of mobility to achieve one European labour market were the major objectives and goals behind the Copenhagen declaration.

A technical working group on quality in VET, with representatives from all Member States as well as representatives from associate countries like Norway was established by the European Commission in 2003. This group of more than 60 members developed a number of quality tools which led to the development of the Common Quality Assurance Framework (European Commission, 2004) in 2004. This framework was based on the four steps in the quality cycle (planning, implementation, evaluation, review) together with a number of indicators for both system and VET provider levels for measuring and documenting quality.

The work on quality continued for the period 2005 to 2009 through the European Network for Quality Assurance in Vocational and Training (ENQAVET) from all European Member States. The outcomes of this group resulted in the recommendation for a European Quality Assurance Reference Framework (EQAVET) (European Parliament and Council, 2009) for VET. Tools aimed at promoting transparency and raising the image of VET were also developed. The European tools of the European Qualification Framework (EQF) (European Parliament and Council, 2008) and the European Credit for Vocational Education and Training (ECVET) (European Parliament and Council, 2009a) recommenddation are among these. While the EQF enabled vocational qualifications to be level rated, it also promoted parity of esteem between vocational and general education. The establishment of ECVET allowed the transfer of credits in vocational education obtained as part of a course of study at one training institution to another.

Since 2010, EQAVET became synonymous with both the network as well as the QA tool developed for VET. The EQAVET model for QA in VET promotes a new culture of quality improvement based on a new governance model (Grek et al., 2009). This EU approach has brought about significant changes in approaching VET, with an orientation towards outcomes and performance, a focus on clients, a new management for schools, transparency, partnership, separation between delivery and evaluation, and self-assessment (Masson et al., 2010). A review carried out by Leonardo project - QALLL in 2012 of the state of art on all quality projects funded by EU highlighted how the Copenhagen Process can be considered as a success in setting quality in VET on the agenda, both at European level, at national level and across a number of sectors.

EQAVET however, is not without its weaknesses. Some EU countries have experienced tensions between state authorities and VET providers or between different stakeholders resulting in a nonlinear development of QA (Simola et al., 2009; Croxford et al., 2009). EQAVET does not elaborate what external QA mechanisms are to be implemented (Masson et al., 2009). There also seems to be a difference between what has been achieved at European level and the actual implementation that has taken place at national level at provider level. A study by the EQAVET Secretariat (2013) shows that there was significant progress among Member States as countries work to establish national QA approaches at system and provider levels compatible with EQAVET. Most countries have consolidated QA at Ministerial/central level which reflects a political commitment. A large number of systems are based on learning outcomes. However, it was also noted that there is lower usage of the EQAVET indicators by VET providers than at system level for both initial and continuous VET. There is a tendency for national 
VET systems to implement indicators for planning and implementation while VET providers use descriptors most at the planning stage. VET providers also use indicators more in the evaluation than in implementation and review phases. The latter tends to reflect VET providers' efforts to meet national requirements with respect to QA. There is also more to be done with respect to stakeholder involvement. Not all national systems include the participation of students/learners as one of the key principles in developing a quality culture. There is also need for more collaboration between VET and higher education. More attention also still needs to be given to the engagement of employers (EQAVET Secretariat, 2013).

Another study carried out in 2013 (Ulicna and Curth, 2013) highlighted how countries considered QA to be primarily about three aspects. Firstly, QA minimises the risk of misuse of public funds by ensuring that providers have the capacity to deliver training that meets minimum quality standards set. Secondly, it ensures coherence of national qualifications system and of qualifications awarded. Thirdly, QA also supports the building of trust and confidence in the VET system by implementing mechanisms that ensure that qualifications are relevant to the labour market (ibid.).

It was noted that most of these system level features were not covered by what countries called explicitly QA. These features, however, may be present but do not form part of official QA measures. Unlike EQAVET, countries' existing QA measures tended to be more specific and concern precise elements of VET systems. In addition, other practices in countries' VET systems were identified which can ensure the quality of VET but are not called/ designated as QA (Ulicna and Curth, 2013).

At provider level, QA instruments were found to either focus on the quality of processes in place to enhance quality; or on the output. The study identified a number of trends with respect to the EQVET descriptors. The descriptor most frequently identified was 'Staff Training Plans'. Management related-descriptors like 'alignment of resources with objectives, and consultation with stakeholders to identify needs' were also frequent. EQAVET-descriptors were considered as 'Early warning plans' while 'Availability of review results' were very rarely identified (Ulicna and Curth, 2013).

The comparison also showed that EQAVET differs to a certain extent from the QA measures in place at provider level as it does not contain any descriptors referring to the adequacy of equipment and infrastructure in a VET-institution. It does not have a focus on customers/ learners and their feedback regarding their learning experience, and does not refer to the quality of information and guidance provided to the learner (Ulicna and Curth, 2013).

The European Commission acknowledged progress in the implementation of EQAVET, but accepted that there is still room for improvement in the development of quality assured VET (Bachmann, 2013). A number of challenges with respect to QA remain. These refer to the application of QA in the use of technologies such as Open Online Courses that are driving change in teaching, learning, assessing, recognising skills and in the way knowledge is acquired. Development in QA needs to keep pace with these changes (Bachmann, 2013). Masson et al. (2009) also highlight the need for sharing good policy practices implemented in the EU and worldwide. However, the main challenge that remains is that of having EQAVET implemented within VET institutions at national level. 


\section{$3 \quad$ Aims and objectives of the study}

This study focused on the degree to which VET providers in the participating countries (Malta, Sweden, Turkey, and Italy) have implemented aspects of QA from the EQAVET indicators developed at European level. It reflects a focus on the implementation of European tools at Member State level. The studies carried out talk about VET providers in general. This study aimed to look into further detail at what type of QA processes VET providers in four countries, three of which are Member States are actually implementing.

The specific aims and objectives of the research thus were:

- finding out at national level what part of EQAVET and which of its indicators are being successfully implemented in the countries involved: Malta, Sweden, Italy and Turkey; and

- what parts or indicators have not been implemented by the VET providers in these countries.

The exercise thus aimed to provide knowledge about what has been achieved in the different partner countries, the lessons learnt by the individual VET providers with respect to implementing QA, as well as the key factors for successful implementation of good QA practices identified by VET providers.

The exercise also served to identify those experiences in the partner countries which refer to the implementation of QA arrangements compatible with EQAVET. It also captured examples of successful practices from individual institutions as well as key lessons that have been learnt by VET institutions with respect to the implementation of QA.

Italy, Malta, Sweden and Turkey present different VET systems and consequently different focus and development of QA in VET. In Italy, in 2012, a National plan for QA was approved by the Ministries of Labour and Education. This plan is gradually being implemented starting from the existing quality assurance models and tools for QA both at national and local level. In Sweden, the responsibility for competence development for post-secondary VET is typically devolved to the VET provider. In Turkey, all VET institutions conduct their education processes under the governance of the Ministry of National Education (MEB) at national and regional level and through the Vocational Education Board which takes decisions and offers proposals to the Ministry on planning, development and evaluation of all vocational training. The General Directorate of Technical Vocational Education formulates and implements policies on the management of VET institutions and students' education. VET education in Malta is provided mainly at post-sixteen level, after completion of compulsory education. The National Commission for Further and Higher Education is the regulatory body in Malta and has in 2014, published the National Standards for Internal Quality Assurance for Further and Higher education. These standards need to be fulfilled for licensing purposes (Ure, 2015).

\section{Methodology}

The main research methodology was quantitative through the use of a questionnaire. A questionnaire was considered an appropriate tool as it enabled the collection of similar data from the different VET institutions from the different European partner countries. 
The questionnaire drawn up collected different data targeting different aspects of QA. The questionnaire first collected data about the institution to develop a profile of the participating VET institutions. The questionnaire then targeted general aspects of QA such as reference to quality in policy documents. It also probed institutions' knowledge of national quality policy documents, and whether VET providers were aware of EQAVET. It also asked for details of the main processes/mechanisms for existing QA processes within the institution. The questionnaire then focused on the quality cycle and what mechanisms of planning; implementation; evaluation; and review, are used. It probed how providers promote a quality culture within the institution. The use of the EQAVET indicators was also included. VET providers were asked to indicate: how the VET institutions cater for the professional development of VET trainers; what processes are in place for the design of new courses; how VET providers identify labour market needs; whether statistics about students are kept and how they are used; whether student questionnaires are used and how these feed into the system to improve training provision; whether there is use of different forms of external evaluation, how outcomes of such exercises are used; as well as whether evaluation reports are published for public consumption.

In developing the research tool, it was acknowledged that although the questionnaire could be self-administered, in order to obtaining accurate and reliable data, researchers in the different countries were to collect data through either face to face meetings or through a phone communication. It was believed that direct discussion with VET providers would increase the validity of the answers obtained and avoid situations where respondents may not realize that some everyday practices are actually aspects of QA. A more realistic picture of actual practices could be collected.

Each of the partner countries collected data from about 15 different VET institutions. Each partner decided on the best VET institutions to contact and whether to collect the data through face to face meetings or over the phone depending on the possible logistics. A total of 62 questionnaires were collected.

Table 1: Distribution of Questionnaires collected across the different countries

\begin{tabular}{llccccc}
\hline Country & Malt & Turke & Sweden & Ital & TOTAL \\
\hline Number & of & 1 & 1 & 1 & 1 & 62 \\
\hline
\end{tabular}

In Italy fifteen educational institutions participating in the research were chosen based on their relevance in the Friuli Venezia Giulia educational framework. In Malta 14 responses from a varied spectrum of VET providers were obtained and covered: public and private provision; large organisational structures and small sector-specific setups; different forms of learning, and varying qualification levels in terms of VET courses. In Turkey 17 VET institutions providing training at different levels: 1 institution is at the level of Work-based learning, 2 of the institutions were at the level of ISCED 4 and all others were at ISCED 3 level. In Sweden the questionnaire was done with 16 providers of Higher Vocational Education institutions, ISCED 4 - Post secondary non-tertiary VET. 


\section{Results}

Quality can be considered as a philosophy and a way of thinking as well as a management tool. In whatever way it is considered, quality is important in ensuring that the education and training provided reflects current labour market needs and equips learners with the necessary skills both for employment as well as for life.

\subsection{Knowledge and formal commitment to quality assurance}

The majority of VET providers indicated that quality is important. However, there were significant differences with respect to whether there was official direct reference to quality in mission statements and/or other policy documents. In Turkey, all VET providers had a direct reference to quality in their policies. In Italy, this amounted to around two thirds, and in Malta, to a little more than half of the institutions. Sweden was the country where there was least official commitment, with less than half of the VET providers referring to quality in their mission statements. These responses show that there do not seem to be great cultural differences between the south and north of Europe. The main difference was Sweden. This does not, however, necessarily reflect a lack of attention to quality. Since in Sweden quality is often perceived as an integral part of the daily activities, VET providers do not feel the need to commit to quality explicitly in their mission statement or in other policies.

Table 2: Existence of national quality policies related to Quality across countries

\begin{tabular}{lcccc}
\hline Response & Malta & Turkey & Sweden & Italy \\
\hline Yes & 12 & 15 & 5 & 10 \\
No & 1 & 0 & 5 & 2 \\
Not sure & 1 & 2 & 6 & 3 \\
TOTAL & $\mathbf{1 4}$ & $\mathbf{1 7}$ & $\mathbf{1 6}$ & $\mathbf{1 5}$ \\
\hline
\end{tabular}

A similar trend was obtained with respect to knowledge about awareness of national policies and guidelines related to QA. The majority of VET providers in Malta, Turkey and Italy stated that they were aware of national quality policies. VET providers in Sweden, however, demonstrated less awareness. The Swedish National Agency for Higher Vocational Education, responsible for QA of higher vocational education (HVE) programmes carries out three different types of inspections; (1) introductory supervision, (2) regular supervisions and (3) supervisions owing to certain circumstances (UNESCO-UNEVOC, 2013). This regular monitoring may have helped make QA an integral part of VET institutions, and thus there is no reason to officially commit to QA.

\subsection{Awareness and implementation of EQAVET}

Only a few of the VET-providers participating stated that they had implemented EQAVET in their institutions. The responses show that at most, some of the VET providers were familiar with EQAVET, some others have just heard about it and some others who had never heard about EQAVET. 
Table 2: Awareness of EQAVET in the different VET institutions across countries

\begin{tabular}{lcccc}
\hline Response & Malta & Turkey & Sweden & Italy \\
\hline $\begin{array}{l}\text { Yes, we implement EQAVET in } \\
\text { our institution }\end{array}$ & 3 & 2 & 1 & 0 \\
Yes, I am familiar with it & 9 & 5 & 2 & 4 \\
$\begin{array}{l}\text { I just heard about it } \\
\text { I have never heard of it }\end{array}$ & 1 & 4 & 10 & 8 \\
TOTAL & 1 & 6 & 3 & 3 \\
\hline
\end{tabular}

Work done and tools developed at European level are still not well known to many VET-providers. Malta is the only country where the majority of the VET-providers are familiar with EQAVET. Malta has coordinated two national projects on EQVET where a number of VET providers were partners and many others attended dissemination seminars. This may explain the trend obtained. The other countries, on the other hand, show that the majority of VET-providers have limited knowledge of EQAVET with Turkey reflecting least awareness. Details about EQAVET are not well known and consequently few are specifically implementing. There is need to make VET institutions aware of EQAVET, and to promote the use of EQAVET tools. These results are similar to those obtained by the European study (EQAVET Secretariat, 2013) where EQAVET was implemented less at VET provider level than system level.

Table 3: Type of QA process/procedure in VET institutions across countries ${ }^{2}$

\begin{tabular}{lcccc}
\hline Country & Malta & Turkey & Sweden & Italy \\
\hline $\begin{array}{l}\text { A department/section/unit } \\
\text { dedicated to QA }\end{array}$ & 3 & 4 & 7 & 1 \\
$\begin{array}{l}\text { A person responsible for QA } \\
\begin{array}{l}\text { Policy/procedure structure to be } \\
\text { followed by staff }\end{array}\end{array}$ & 2 & 15 & 2 & 7 \\
$\begin{array}{l}\text { No reply } \\
\begin{array}{l}\text { Number of responding VET } \\
\text { institutions }\end{array}\end{array}$ & 1 & 0 & 0 & 0 \\
\hline
\end{tabular}

Not implementing EQAVET does not necessary imply that VET providers do not have QA systems. Responses obtained identified different ways in which VET providers cater for QA. All providers in Turkey, and about half of those in Italy assign QA responsibilities to a specific person. This is not the case for Malta and Sweden. In Sweden, there tends to be a department dedicated specifically to quality. A common approach across the countries is that of having procedures and processes at institution level which are followed by staff, whether or not a department or person is designated to QA. Differences in approach may not reflect only national trends but also the size of the institution. Larger institutions may opt

\footnotetext{
${ }^{2}$ Note: Respondents could choose more than one option
} 
for QA departments, while smaller institutions prefer to have designated individuals. Trends could also reflect whether QA is centralized or decentralised.

\subsection{Implementation of the quality cycle and use of EQVET indicators}

EQAVET is based on the quality cycle: planning; implementation; evaluation; and review. The responses obtained show that in Malta, about half of the VETproviders either use the quality cycle or have quality processes in each of the phases. However, one third are not aware of any particular processes for each of these phases. Sweden, Italy and Turkey, on the other hand, reflect a similar trend with most VET providers implementing EQAVET or have processes for each of these phases. Although in Malta VET providers are familiar with EQAVET, the quality cycle is not really utilised. On the other hand, in Turkey, Italy and Sweden, where there is less knowledge of EQAVET, there is more use of the quality cycle.

Table 4: Frequency of use of the quality cycle across partner countries

\begin{tabular}{lcccc}
\hline Country & Malta & Turkey & Sweden & Italy \\
\hline $\begin{array}{l}\text { We use the quality cycle officially } \\
\text { We do not use it officially but we } \\
\text { have quality process in each of }\end{array}$ & 2 & 11 & 10 & 8 \\
$\begin{array}{l}\text { these phases } \\
\begin{array}{l}\text { I am not aware of any particular } \\
\text { processes for each of these phases }\end{array}\end{array}$ & 5 & 0 & 4 & 6 \\
$\begin{array}{l}\text { No reply } \\
\text { TOTAL }\end{array}$ & 1 & 0 & 0 & 0 \\
\hline
\end{tabular}

A quality culture is difficult to achieve as it is intangible. However, it is necessary for successful implementation of QA processes. Most providers indicated that they believe having a quality culture within their institution which can be demonstrated through different activities e.g.: working with all processes throughout the complete quality cycle; implementing a common decision process; and determining problems and setting objectives based on principles created by all staff. With respect to transparency, all countries except Sweden stated that they publish different types of quality reports that they produce. However, few VET providers publish reports on evaluation of courses, these mainly done in Turkey.

Designing new courses at planning stage is an important activity at all levels of education. All VET providers in Sweden, the majority of VET-providers in Turkey and Italy, but only half of the VET-providers in Malta have official processes for the design of new courses. These trends reflect similar responses to the implementation of EQAVET where Malta declared the least degree of implementation and use of the quality cycle.

Another EQAVET indicator at planning stage refers to the professional development of VET teachers. Similarities across all project partner countries were obtained where half of VET providers in Malta, Sweden and Italy and the majority in Turkey stated that they are committed to VET trainers' professional development. 
Table 5: Type of Professional development supported by VET institutions ${ }^{3}$

\begin{tabular}{|c|c|c|c|c|}
\hline Country & Malta & Turkey & Sweden & Italy \\
\hline $\begin{array}{l}\text { Have official policy on training of } \\
\text { VET teaching staff }\end{array}$ & 5 & 9 & 6 & 5 \\
\hline $\begin{array}{l}\text { Dedicate budget for professional } \\
\text { development for VET trainers }\end{array}$ & 4 & 4 & 8 & 2 \\
\hline $\begin{array}{l}\text { Participate in EU mobility } \\
\text { programmes for VET Staff e.g. } \\
\text { Leonardo }\end{array}$ & 4 & 10 & 1 & 4 \\
\hline $\begin{array}{l}\text { Document and publish VET trainers' } \\
\text { CPD every year }\end{array}$ & 1 & 3 & 2 & 1 \\
\hline Other - in service training & 2 & 12 & 0 & 0 \\
\hline
\end{tabular}

There exist many ways of supporting the development of the teachers e.g. as mentioned in Turkey: by having an official policy on training of teachers, having a dedicated budget to teacher-training, participating in EU-mobility projects, and documenting and publishing VET-trainers' continuous professional development every year. In Turkey the most prominent form of trainers' professional development is through in-service training provided by the Ministry of Education. They also participate in EU projects.

Professional development within VET institutions are present to different degrees in the participating VET providers in the different countries involved. More VET providers in Sweden have a dedicated budget than in the other partner countries. The countries differ also with respect to using EU mobility programmes for VET staff, which are used most in Turkey, and least in Sweden. Very few of the VET providers in all the four partner countries document and publish VET trainers' professional development experiences.

In Sweden all the VET-providers carry out labour needs analysis. They claim that they organize meetings with employers and other stakeholders, carry out surveys, as well as tracer studies among their past students. Different trends were obtained in the other countries. In Turkey, many of the VET providers carry out tracer studies, but few have meetings or surveys. In Italy, all the VET providers use regular meetings and many also carry out tracer studies. Only half of the VET providers in Italy use surveys. In Malta, all the VET providers carrying out needs analysis use meeting and committees, but only few carry out surveys and tracer studies.

The evaluation phase demonstrates a high degree of similar processes used across the VET providers in the different countries. Activities include formal teacher and student evaluations; performance and project tasks and exams. There is a different degree of use of student questionnaires. All the VET providers in Sweden use student questionnaires. A good number of the VET providers in Italy and Malta also use them. It is only in Turkey that a little more than half of the VET

\footnotetext{
${ }^{3}$ Note: respondents could choose more than one option.
} 
providers use student feedback forms. In some countries like Turkey it is not compulsory to use questionnaires - the decision is up to the individual provider. Student questionnaires are also used in different ways. In Sweden, the VET trainer is shown his student evaluation. The responses are also fed into evaluation reports, as well as used to take action when needed. The trend is, however, different in Malta, where the main use of the student questionnaires is to take action on the performance of the VET trainer.

Different types and degree of use of external evaluation was identified. In Italy, all VET providers use a form of external evaluation. This was present in 12 out of the 16 in Sweden, while a little more than half of the VET providers in Malta and Turkey use evaluation. In Turkey there is no form of external evaluation of VET providers. However, some providers still use external evaluations. In Sweden there does not appear to be a practice to have external evaluators for single courses. Around half of the VET providers in Italy, Turkey and Sweden have external evaluation of whole courses and education provision. This is not usual in the case of Malta with only three VET providers having a system of external evaluation. Turkey is the country where there is the largest number of VET providers using external evaluation of individual courses.

The review-phase of the quality cycle is handled differently across the partner countries. Evaluations are used to make changes if they are to contribute to the overall quality of the education and training provided. All the VET providers in Malta, Italy and Sweden stated that they take action on the result of external evaluation. This was only the case for half of the VET providers in Turkey. VET providers across all countries indicated various actions taken as a result of the outcomes of external evaluation. The most common actions were present in Sweden and included updating modules, designing new courses, as well as investing in continuous professional development and to improve assessment processes. This is done to a lesser degree in Italy and Malta with respect to further investment in professional development of trainers.

Table 6: Frequency of type of statistics kept by VET institutions across partner countries ${ }^{4}$

\begin{tabular}{lcccc}
\hline Country & Malta & Turkey & Sweden & Italy \\
\hline $\begin{array}{l}\text { Number of students registered in } \\
\text { the separate courses }\end{array}$ & 14 & 17 & 16 & 13 \\
$\begin{array}{l}\text { Number of drop outs by the end of } \\
\text { the year }\end{array}$ & 13 & 17 & 16 & 12 \\
$\begin{array}{l}\text { Tracer study (in employment or } \\
\text { further study) on completion of } \\
\text { studies }\end{array}$ & 4 & 17 & 16 & 8 \\
\hline
\end{tabular}

There seems to be limited value given to quality manuals and to the EQAVET website and toolbox. In Turkey the two main tools and activities considered helpful for QA included: the standards and guidelines published by National Authorities and the sharing practices with other VET institutions. In Sweden the major tools used by VET providers were the national standards and guidelines published by National Authorities and the manuals for implementing QA. In Malta and in Italy a broad range of tools were mentioned. The EQAVET website/toolbox was only

\footnotetext{
${ }^{4}$ Note: respondents could choose more than one option
} 
mentioned by few of the VET-providers in each country, which raises questions about why and if/how this can be promoted more among VET providers. The use of external consultants and foreign institutions is also very limited and only a few VET-providers in Malta and Italy mentioned it.

All the VET-providers consider the quality cycle and/or the whole Quality Management System as key for success for implementation within the planningphase. VET provides also emphasized the importance of links to the labour market and the standards and guidelines from the national authorities. At implementation phase, Vet providers identified various key success factors such as the introduction of learning outcomes, the use of work based learning and close contact with the labour market. The most successful processes within the evaluation-phase were self-evaluation, external evaluation, inspection from national authorities, as well as a number of different questionnaires to the students and even to the labour market. A common emphasis included the participation and involvement of many different actors e.g. teachers and trainers, internal and external committees with relation to the labour market. The quality of the person responsible for QA at the individual VET-provider was also considered important.

\subsection{Advice to others}

The responding VET-providers provided similar type of advice for the planning phase. They highlight the need to focus on local needs and to have a structured mechanism to communicate with the labour market. VET providers also highlighted the importance of creating a quality system designed and adapted to the individual VET-provider. They also identified the need to factor in the time of work needed and the internal resources required when planning new courses. Advice on the implementation phase referred to the importance of having internal standardized procedures for QA, investing in time and resources, securing internal cooperation and creating a positive rivalry between students. Advice on the evaluation phase highlighted how important it is to accept criticism from both external and internal stakeholders, and to include a broad involvement of players in the analysis of the evaluations. In the review phase VET providers recommended using the analysis of responses obtained, securing follow-up and giving feedback to students and all stakeholders. The responding VET-providers also highlighted the importance of involving different actors, to listen to the market needs and meet the professionals, consider input by all stakeholders seriously and involve them in the process. They also highlighted the need to educate trainers through professional development.

\subsection{Lessons learnt}

VET providers mentioned a range of examples of lessons learnt and which they believed that other VET providers could also learn from. At planning stage, VET providers in all countries mentioned the need for planning and appreciating the benefits of continuous improvement. It was Italy and Malta only who acknowledged the need for customized quality systems and for written procedures. Providers also highlighted the need for standards and clear guidelines for learning hours and study plans. At implementation phase, one lesson learnt was the need to have both a good and well balanced committed team that believes in quality, supervision, limited bureaucracy as well as is able to communicate clearly. They also highlighted the need for ICT support and in investing in a data management 
System. Vet providers indicated how evaluation has to be carried out regularly and to be monitored. They highlighted how in the review process there needs to be a systematic link between evaluations and the design of new courses. Involvement of key actors is also considered essential to ensure quality of training provision.

\section{Discussion}

This research provides further insights about what is actually happening at VET provider level in addition to what is known from the two main studies carried out (EQAVET secretariat, 2013; Ulicna and Curth, 2013). Like these two studies, this study highlights that there are aspects of EQAVET being implemented at VET provider level in the countries involved. However, these existing QA practices are not necessarily a direct result of EQAVET, but more so, of VET providers' commitment to improve the quality of their service as well as to fulfill national quality needs to achieve accreditation (CEDEFOP, 2011). As VET institutions provide education and training, they develop processes and systems in response to their institution's needs. These processes reflect the providers' commitment to QA, based on employers' and trainees' feedback, to capture the labour market outcomes of training (ILO, 2010). VET providers often utilise QA to get through an accreditation and external or internal review process, but widespread use of the EQAVET cycle is not common (European Commission, 2014).

The limited knowledge of and familiarity with the European QA tools is a concern. With the exception of Malta, this study highlights that little knowledge about EQAVET has seeped down to provider level. In Malta, although many VET providers are familiar with EQAVET, few are implementing it. On the other hand, even if VET providers and VET teachers in the other countries may not be aware of developments at European level and about EQAVET, there are still positive signs with respect to QA development at VET provider level.

A common approach to QA in the four countries is to use the quality cycle as the majority of the VET institutions in the study, intentionally or not, were found to use the quality cycle to implement QA across the various activities. There is agreement on the effectiveness and usefulness of the quality cycle, whether as part of EQAVET or not.

The implementation of EQAVET at national level faces a number of challenges. Besides the national differences and differences in context, one finds common challenges. Projects aiming at the national implementation of EQAVET supported by the European Commission highlight several of these challenges. These relate to: how to create a shared culture of QA and improvement; how to involve stakeholders and keep them involved in QA and innovation in VET; how to deal with existing policies and QA systems at both system and providers' level; and how to ensure the sustainability of the initiatives in order to make the implementation of the EQAVET framework a reality (European Commission, 2013).

This study sheds some light on how to face to the challenge of dealing with existing QA processes. Different approaches and processes to those developed by EQAVET have been identified in the VET providers in the study. None the less, these QA processes are considered to be as effective in ensuring quality. The results thus highlight how quality can be given its due attention through other systems and processes than those of EQAVET. If EQAVET is presented as a model on which to build and develop further existing QA processes, it is not a problem that there are other approaches in place parallel to or performing a similar 
function to those specified within EQAVET. EQAVET's role at national level can evolve from the tool that is to be implemented as is by VET institutions as it to a tool to inspire VET institutions (EQAVET, n.d.). This alternatively leads one to question whether it would be possible to achieve more if the discussion were to focus on principles of quality rather than on the specific implementation of EQAVET as the European model for quality in VET.

While the work that has been produced within EQAVET is rich, a lot of it still needs to reach many VET institutions. The research results show that VET institutions already possess elements of quality. It could thus not make sense for VET providers to take EQAVET and implement it lock, stock and barrel when they all have a legacy of quality assurance practices which are probably already serving their purpose well. None the less, QA in VET has a significant role. Particularly, VET qualifications are linked to the overall quality of these processes and may be negatively affected if any doubt arises (CEDEFOP, 2009). There surely is much that VET institutions can take and learn from EQAVET.

\section{Conclusions from the PEN-project}

This study has shown that there is need for more dissemination about EQAVET and the EQAVET website, as well as in the use of the quality cycle at national level. A good approach would be the use of examples of good practice to provide inspiration for other VET providers. Links between European level, national level and provider level definitely need to be strengthened. There should be more sharing of practices at both national and international level among VET providers both within and across sectors. This can be achieved through projects which document good practice and used to promote QA processes across the different VET providers. VET providers can share the use of indicators and how they use the outcomes of QA to improve their training. Lessons learnt by VET providers can be compiled and published, and used to promote better practices at National and European level.

While a lot has been achieved since the beginning of the Copenhagen Process, the challenge of ensuring quality assurance structures which cover all the parts and aspects of the quality cycle still has some way to go in order to achieve a quality European VET area. The impact of quality measures in the provision of education and training which is beneficial at individual, national and European level should continue to be stressed for better employment opportunities for European citizens and a better, more competitive Europe. 


\section{References}

Bachmann, D.C. (2013). EQAVET Newsletter Editorial December 2013, EQAVET Newsletter 8.

Boden, M., Cagnin, C., Carabin, V., Haegeman, K., \& Konnola, T., (2010). Facing the Future: time for the EU to face Global Challenges. Seville: Joint Research Centre, Institute for Prospective Technological Studies.

CEDEFOP (2009). The relationship between quality assurance and VET certification in EU Member States. Luxembourg: Office for Official Publications of the European Communities.

CEDEFOP (2011). Assuring quality in vocational education and training. The role of accrediting VET providers. Luxembourg: European Centre for the Development of Vocational Training.

Croxford, L., Grek, S. \& Jeelani Shaik, F. (2009). Quality assurance and evaluation in Scotland: promoting self-evaluation within and beyond the country, Journal of Education Policy 24, 179-193.

EQAVET Secretariat (2013). Supporting the implementation of the European Quality Assurance. Dublin: EQAVET Secretariat.

EQAVET (N.D.), VET providers' self-monitoring by using the EQAVET toolbox of indicators (A Guide for National Reference Points). Dublin: EQAVET Secretariat.

European Commission (2004). Fundamentals of a 'Common Quality Assurance Framework' (CQAF) for VET in Europe. Brussels: European Commission.

European Commission (2010). Europe 2020: A European Strategy for a smart, sustainable, and inclusive growth. Brussels: European Commission.

European Commission (2013). EQAVET implementation: "A European goal to be national approaches" achieved through We have applied EQAVET: EQAVET Projects 2011 - 2013 the experiences of the EQAVET pilot projects. Brussels: EQAVET European Conference on Quality in VET.

European Commission (2014). Report from the Commission to the European Parliament and the Council on the implementation of the Recommendation of the European Parliament and of the Council of 18 June 2009 on the establishment of a European Quality Assurance Reference Framework for Vocational Education and Training. Retrieved from http://www.parlament.gv.at/PAKT/EU/XXV/EU/02/55/EU_25554/imfname 10467219.pdf on 31. January 2016.

European Ministers of VET and the European Commission (2002). Declaration of the European Ministers of Vocational Education and Training, and the European Commission, convened in Copenhagen on 29 and 30 November 2002, on enhanced European cooperation in vocational education and training "The Copenhagen Declaration”. Brussels: Official Journal of the European Union.

European Ministers of Vocational Education and Training and the European Commission (2002). The Copenhagen Declaration, Declaration of the European Ministers of Vocational Education and Training, and the European Commission, convened in Copenhagen on 29 and 30 November 2002, on enhanced European cooperation in vocational education and training. Brussels: Official Journal of the European Union. 
European Parliament and Council (2009). Recommendation of the European Parliament and of the Council of 18 June 2009 on the establishment of a European Quality Assurance Reference Framework for Vocational Education and Training (2009/C 155/01).

European Parliament and Council (2008). Recommendation of the European Parliament and of the Council of 23 April 2008 on the establishment of the European Qualifications Framework for Lifelong Learning. Brussels: Official Journal of the European Union.

European Parliament and Council (2009). Recommendation of the European Parliament and of the Council of 18 June 2009 on the establishment of a European Quality Assurance Reference Framework for Vocational Education and Training. Brussels: Official Journal of the European Union.

European Parliament and Council (2009). Recommendation of the European Parliament and of the Council of 18 June 2009 on the establishment of a European Credit System for Vocational Education and Training (ECVET). Brussels: Official Journal of the European Union.

Galvao, M.E. (2014). Making the Case for Vocational Education and Training improvement: Issues and challenges. Turin: European Training Foundation.

Grek, S., Lawn M., Lingard B., \& Varjo, J. (2009). North by Northwest: quality assurance and evaluation in European Education. Journal of Education Policy 24, 121-133.

International Labour Office (ILO) (2010). A Skilled Workforce for Strong, Sustainable and Balanced Growth: A G20 Training Strategy, Geneva: ILO.

Jørgensen, C. (2014). The current state of the challenges for VET in Denmark. Copenhagen: Nord-VET - The future of VET in the Nordic Countries.

Lisbon Special European Council (2000). Towards a Europe of Innovation and Knowledge. Lisbon: Lisbon Special European Council.

Masson, J., Baati, M., \& Seyfried E. (2010). Quality and Quality Assurance in Vocational Education and Training in the Mediterranean Countries: lessons from the European Approach. European Journal of Education 45(3), 514-526.

OECD (2010). Learning for Jobs. Paris: OECD Publishing.

Seyfried, E. (2008). Quality and Quality Assurance in Technical and Vocational Education and Training. Turin: European Training Foundation.

Simola, H., Rinne, R.,Varjo, J., Pitkanen, H., \& Kauko, J. (2009). Quality assurance and evaluation in Finnish compulsory schooling: a national model or just unintended effects of radical decentralisation? Journal of Education Policy 24, 163-178.

Ulicna, D., \& Curth, A. (2013). Study on Quality Assurance in Continuous VET and on future development of EQAVET. Brussels: ICF GHK.

UNESCO-UNEVOC (2013). World TVET Database Sweden. Bonn: Germany.

Ure, O.B. (2015). Governance for Learning Outcomes in European Policy-Making: Qualification Frameworks Pushed through the Open Method of Coordination. International Journal for Research in Vocational Education and Training 2(4), 268-283. doi: 10.13152/IJRVET.2.4.2. 